\title{
Modulation of Excitability by $\alpha$-Dendrotoxin-Sensitive Potassium Channels in Neocortical Pyramidal Neurons
}

\author{
John M. Bekkers and Andrew J. Delaney \\ Division of Neuroscience, John Curtin School of Medical Research, Australian National University, Canberra, ACT 0200, \\ Australia
}

\begin{abstract}
Many neurons transduce synaptic inputs into action potentials (APs) according to rules that reflect their intrinsic membrane properties. Voltage-gated potassium channels, being numerous and diverse constituents of neuronal membrane, are important participants in neuronal excitability and thus in synaptic integration. Here we address the role of dendrotoxin-sensitive "D-type" potassium channels in the excitability of large pyramidal neurons in layer 5 of the rat neocortex. Low concentrations of 4-aminopyridine or $\alpha$-dendrotoxin ( $\alpha$-DTX) dramatically increased excitability: the firing threshold for action potentials was hyperpolarized by $4-8 \mathrm{mV}$, and the firing frequency during a 1-sec-long 500 pA somatic current step was doubled. In nucleated outside-out patches pulled from the soma, $\alpha$-DTX reversibly blocked a slowly inactivating potassium current that comprised $\sim 6 \%$ of the total. This current first turned on at
\end{abstract}

Many classes of neurons function as transducers that convert patterns of (input) synaptic potentials into patterns of (output) action potentials (APs), which then propagate information to other neurons. This transduction process, called synaptic integration, is often highly complex and depends on, among other things, the types and distribution of ion channels that populate the neuronal membrane (Häusser et al., 2000). One of the major determinants of AP firing is voltage-gated potassium channels, which tend to dampen or pace electrogenic activity (Hille, 1992). Thus, to fully understand synaptic integration, it is important to know the disposition of the various types of voltage-gated potassium channels that are found on the somata and dendrites of neurons.

In recent years synaptic integration has been intensively studied in the large pyramidal neurons with somata that are located in layer 5 of mammalian neocortex (Stuart et al., 1997b). These neurons are attractive subjects because of their unusually accessible apical dendrites and their importance as the main output neurons of the cortex. To date, the function and distribution of $\mathrm{Na}^{+}$channels (Stuart and Sakmann, 1994), $I_{\mathrm{h}}$ channels (Williams and Stuart, 2000; Berger et al., 2001) and two types of voltage-

\footnotetext{
Received April 5, 2001; revised June 22, 2001; accepted June 26, 2001.

The work was supported by recurrent funding from the John Curtin School of Medical Research. We thank Drs. Pankaj Sah and Greg Stuart for comments on this manuscript.

Correspondence should be addressed to Dr. J. M. Bekkers, Division of Neuroscience, John Curtin School of Medical Research, GPO Box 334, Canberra, ACT 2601, Australia. E-mail: John.Bekkers@anu.edu.au.

A. J. Delaney's present address: Vollum Institute L474, Oregon Health Sciences University, 3181 S.W. Sam Jackson Park Road, Portland, OR 97201.

Copyright (C) 2001 Society for Neuroscience $\quad 0270-6474 / 01 / 216553-08 \$ 15.00 / 0$
}

voltages just hyperpolarized to the threshold for spiking and activated steeply with depolarization. By assaying $\alpha$-DTXsensitive current in outside-out patches pulled from the axon and primary apical dendrite, it was found that this current was concentrated near the soma. We conclude that $\alpha$-DTXsensitive channels are present on large layer 5 pyramidal neurons at relatively low density, but their strategic location close to the site of action potential initiation in the axon may ensure that they have a disproportionate effect on neuronal excitability. Modulation of this class of channel would generate a powerful upregulation or downregulation of neuronal output after the integration of synaptic inputs.

Key words: action potential; D-current; dendrite; dendrotoxin; neocortex; potassium channel; pyramidal neuron gated $\mathrm{K}^{+}$channels $\left(I_{\mathrm{A}}\right.$ and delayed rectifier channels) (Bekkers, 2000a,b; Korngreen and Sakmann, 2000) have been studied in this type of cell.

Another member of the class of voltage-gated $\mathrm{K}^{+}$channels, frequently reported in other types of neurons, is the D-current $\left(I_{\mathrm{D}}\right)$, which was originally identified by its ability to delay the firing of APs after a depolarizing current step (Storm, 1988). $I_{\mathrm{D}}$ is now more commonly defined by its slow inactivation kinetics and sensitivity to low concentrations of 4-aminopyridine (4-AP) and dendrotoxin (DTX) (Storm, 1993; Coetzee et al., 1999). 4-AP (50-100 $\mu \mathrm{M})$ was reported to have no effect (Bekkers, 2000a), and dendrotoxin little effect (Korngreen and Sakmann, 2000), on nucleated outside-out patches pulled from the somata of large layer 5 pyramidal neurons, suggesting that $I_{\mathrm{D}}$ is only weakly expressed in these cells (Albert and Nerbonne, 1995). However, an immunocytochemical study has shown that the major apical dendrites of large layer 5 neurons are particularly enriched in Kv1.2 subunits, whereas the cell bodies are relatively spared of Kv1.2 staining (Sheng et al., 1994). The Kv1.2 subunit, probably in combination with other $\mathrm{Kv}$ proteins and $\mathrm{Kv} \beta$ subunits, is thought to comprise $I_{\mathrm{D}}$ channels (Coetzee et al., 1999). Thus, the earlier work might have missed significant $I_{\mathrm{D}}$ current by confining the search to somatic membrane. We therefore decided to revisit this question by exploring the possibility that $I_{\mathrm{D}}$ is preferentially expressed in the dendrites.

We find that these large layer 5 cortical neurons do, indeed, contain $I_{\mathrm{D}}$-like channels, as revealed by a marked increase in excitability in 4-AP or $\alpha$-DTX and by the presence of a small $\alpha$-DTX-sensitive current in outside-out patches. Surprisingly, despite the immunocytochemical evidence, these channels tend to be concentrated close to the soma in the axon and primary apical 
dendrite. With this distribution, the channels are ideally placed to influence neuronal output.

\section{MATERIALS AND METHODS}

Neocortical slices (300 $\mu \mathrm{m}$ thick) were prepared from 14- to 21-d-old Wistar rats using standard techniques that were approved by the Animal Experimentation Ethics Committee of the Australian National University (Bekkers, 2000a). Large layer 5 pyramidal neurons in sensorimotor cortex were identified and patch electrodes were positioned using infrared videomicroscopy. Experiments used slices in which the primary apical dendrites were most nearly parallel to the cut surface, to minimize damage to the dendritic tree. Recordings were made with a MultiClamp 700A computer-controlled patch-clamp amplifier (Axon Instruments, Foster City, CA), the headstage of which contains both an Axopatch-like voltage-clamp circuit and an Axoclamp-like voltage follower for true current clamp. In voltage-clamp mode, linear leak and capacitance currents were removed using an on-line subtraction procedure, as described previously (Bekkers, 2000a). When recording from nucleated outside-out patches, $80-90 \%$ series resistance compensation was applied, minimizing steady-state voltage errors to $<1 \mathrm{mV}$. Currents were filtered at $2 \mathrm{kHz}$ and digitized at $10 \mathrm{kHz}$. Current clamp recordings in whole-cell mode used bridge balance and capacitance neutralization, which were checked throughout the experiment. Families of current injections, done at $4 \mathrm{~min}$ intervals, were repeated at least three times in control and test solutions, and the measurements in each condition were averaged together. Voltages were filtered at $10 \mathrm{kHz}$ and digitized at $20-50 \mathrm{kHz}$. Patch electrodes had resistances of 3-5 M $\Omega$ (whole-cell or nucleated patches) or 7-12 $\mathrm{M} \Omega$ (outside-out patches).

The usual bath solution comprised (in $\mathrm{mm}$ ): $125 \mathrm{NaCl}, 3 \mathrm{KCl}, 25$ $\mathrm{NaHCO}_{3}, 1.25 \mathrm{NaH}_{2} \mathrm{PO}_{4}, 1 \mathrm{MgCl}_{2}, 2 \mathrm{CaCl}_{2}, 25$ glucose, $\mathrm{pH} 7.4$, when saturated with $95 \% \mathrm{O}_{2} / 5 \% \mathrm{CO}_{2}$, plus $10 \mu \mathrm{M} \mathrm{CNQX}$ to inhibit excitatory synaptic transmission. In experiments with $\alpha$-DTX, $0.1 \%$ bovine serum albumin was also added (Martina et al., 1998). In some experiments (e.g., see Fig. 5), a high-TEA bath solution was used, in which $30 \mathrm{~mm}$ tetraethylammonium chloride substituted for $30 \mathrm{~mm}$ of the $\mathrm{NaCl}$. Internal solution comprised (in $\mathrm{mM}$ ): 135 potassium methylsulfate, $7 \mathrm{NaCl}, 5$ EGTA, 2 MgATP, 0.3 GTP, 10 HEPES, adjusted to pH 7.2 with KOH. All voltages have been corrected for the measured junction potential of these solutions $(-7 \mathrm{mV})$. Drugs were dissolved in bath solution and applied either by Picospritzer (General Valve, Fairfield, NJ) or by perfusing the bath volume $>10$ times. Control experiments confirmed that Picospritzer ("puffer") application of external solution alone (without drugs) had no effect on any of the measurements. Also, in experiments using the puffer to apply $\alpha$-DTX to outside-out patches (see Fig. 7), correct application of the toxin was checked at the end of the day by confirming that the puffer produced the expected increase in whole-cell excitability (see Fig. 2). All compounds were obtained from Sigma (St. Louis, MO), apart from CNQX (Tocris Cookson, Bristol, UK) and $\alpha$-DTX (Alomone, Jerusalem, Israel). All experiments were performed at room temperature $\left(22-25^{\circ} \mathrm{C}\right)$.

Analysis was done using AxoGraph (Axon Instruments). Instantaneous AP frequency was calculated from the reciprocal of the time between successive AP peaks. The voltage threshold for AP firing was determined as the interpolated membrane potential $\left(V_{\mathrm{m}}\right)$ at which $d V_{\mathrm{m}} / d t$ equaled $20 \mathrm{~V} / \mathrm{sec}$; this criterion gave the best agreement with threshold determinations done by eye (e.g., see Fig. 3). AP half-width was measured at half the difference between the firing threshold and the peak of each AP. Input resistance was estimated from the steady-state voltage response to a long $(1 \mathrm{sec})$ hyperpolarizing current step $(100 \mathrm{pA})$. Amplitudes of currents in nucleated and outside-out patches were measured by averaging over a window $100-150 \mathrm{msec}$ after the beginning of the voltage step to the test potential. Inhibition by $\alpha$-DTX was calculated by dividing the mean amplitude measured during toxin application by the average amplitudes measured before and after toxin application (e.g., see Figs. $4 B, 5 A, 7 A)$. To generate activation plots, currents were converted to conductances using the measured reversal potential for the delayed rectifier current in nucleated patches from these neurons $(-85 \mathrm{mV})$ (Bekkers, 2000a). The plots were fitted to the Boltzmann equation, $f(V)=G_{\max } /\left(1+\exp \left(\left(V_{1 / 2}-V\right) / k\right)\right)$, where $G_{\max }$ is the maximal conductance, $V_{1 / 2}$ is the voltage at which activation is half-maximal, and $k$ is the slope factor. To generate normalized activation plots (see Fig. 5), the data from each cell were normalized by the fitted $G_{\max }$, and all cells were averaged together. Statistical comparisons used the $t$ test. Errors are given as \pm SEM, with $n$ the number of cells or patches.

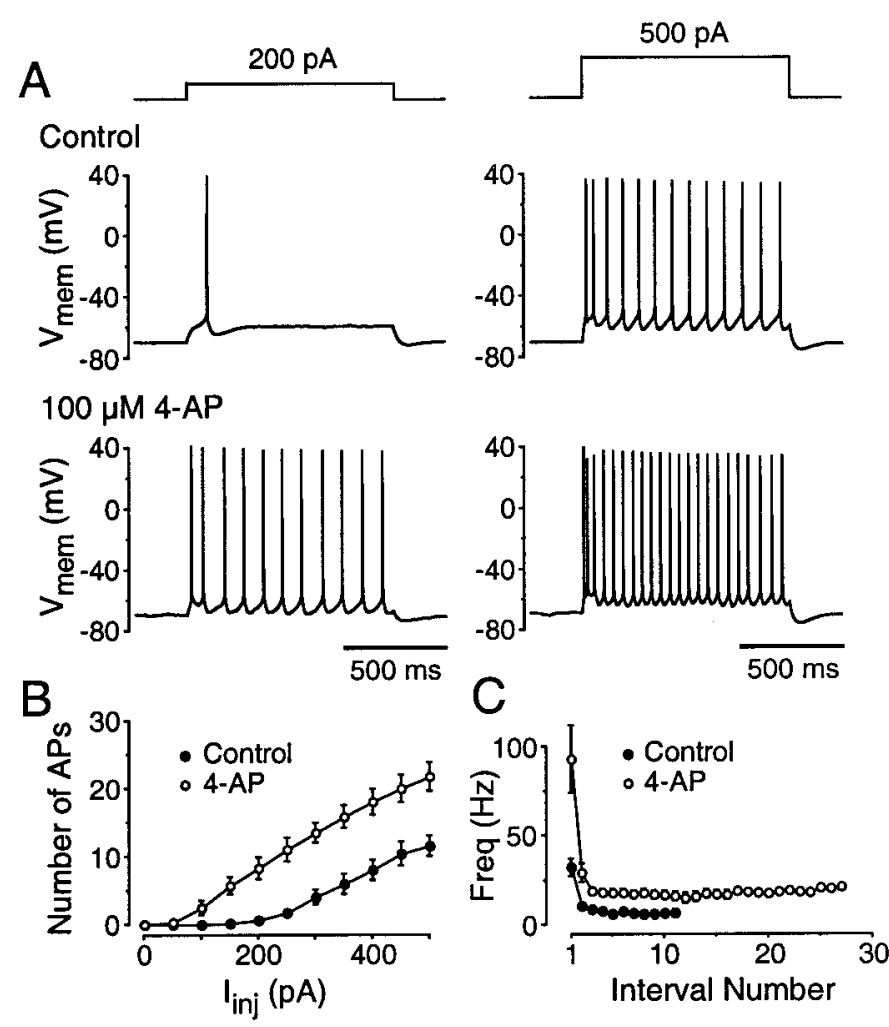

Figure 1. Bath application of $100 \mu \mathrm{M}$ 4-AP increases the excitability of large layer 5 cortical pyramidal neurons. A, Action potentials (APS) elicited by 1 -sec-long $200 \mathrm{pA}$ (left) or $500 \mathrm{pA}$ (right) current steps in the same neuron before (top) or after (bottom) addition of $100 \mu \mathrm{M}$ 4-AP to the external solution. For this neuron, 200 pA was just suprathreshold for the firing of an AP in control solution. Note that all membrane potentials have been corrected for the measured liquid junction potential $(-7 \mathrm{mV}$; see Materials and Methods). $B$, Mean number of APs elicited by 1 -seclong current steps to the values given on the $x$-axis $(\bullet$, Control; $\bigcirc, 4-A P$; $n=6$ cells; \pm SEM). 4 -AP reduces the amount of current required to fire APs. $C$, Mean instantaneous AP frequency (i.e., reciprocal of interval between adjacent APs) versus the interval number, measured during a 1 -sec-long $500 \mathrm{pA}$ current step. Same data set and symbols as in B. 4-AP increases the firing rate of APs during a fixed current step.

\section{RESULTS}

\section{4-AP (100 $\mu \mathrm{M})$ increases neuronal excitability}

A defining property of D-type potassium current in hippocampal pyramidal neurons is its sensitivity to both $\alpha$-dendrotoxin and low concentrations of 4-aminopyridine (Storm, 1988; Wu and Barish, 1992; Golding et al., 1999). We began by examining the effect of $100 \mu \mathrm{M} 4$-AP on the firing properties of large layer 5 cortical pyramidal neurons.

Excitability was assayed by injecting 1-sec-long steps of current at the soma under current clamp (Fig. $1 A$ ). Adding $100 \mu \mathrm{M} 4-\mathrm{AP}$ to the bath consistently increased the excitability of all neurons tested. This occurred despite any significant change in both the resting potential $(-73.5 \pm 0.9 \mathrm{mV}$ in control, $-72.2 \pm 0.8 \mathrm{mV}$ in 4-AP; $n=6 ; p>0.16$, paired $t$ test) and the input resistance $(42.7 \pm 2.7 \mathrm{M} \Omega$ in control, $46.1 \pm 3.0 \mathrm{M} \Omega$ in $4-\mathrm{AP} ; p>0.08)$ of the neurons. Excitability changes were quantified in two ways (Fig. $1 B, C$ ). Changes in the current required for firing action potentials were determined by plotting the number of APs evoked during each current step versus the amplitude of this injected current (Fig. $1 B$ ). Addition of $100 \mu \mathrm{M}$ 4-AP shifted the plot to the left, indicating that less current was required to generate the same 
number of APs in 4-AP. The mean threshold current (the minimum injected current that fires APs) was $221 \pm 18 \mathrm{pA}$ in control solution and $110 \pm 14 \mathrm{pA}$ in $100 \mu \mathrm{M} 4-\mathrm{AP}$ ( $n=6$ cells; significantly different, $p<0.01$ ).

The second measure of excitability quantified the rate of AP firing during a current step of fixed amplitude (500 pA). The instantaneous AP frequency, calculated from time intervals between successive APs, was plotted versus the interval number in the train (Fig. 1C). Addition of $100 \mu \mathrm{M}$ 4-AP significantly increased the AP frequency throughout the train.

The neuron in Figure $1 A$ is representative of the majority of neurons in this study (24/28 tested) in that it fired a burst of two or three APs at the start of larger current steps, then fired regularly without accommodating. This behavior is typical of large layer 5 neurons in rats of this age (Kasper et al., 1994; Williams and Stuart, 1999). Of the remaining neurons in the sample, three weakly accommodated and one showed strong burst firing; these were not included in the analysis.

\section{$\alpha$-DTX (1-2 $\mu \mathrm{M})$ also increases excitability}

Low concentrations of 4-AP may partially block the A-type potassium current in pyramidal neurons, causing changes in excitability and confounding the effect of $I_{\mathrm{D}}$ blockade (Hoffman et al., 1997; Bekkers, 2000a; Korngreen and Sakmann, 2000). Accordingly, we repeated the above experiments with the more selective $I_{\mathrm{D}}$ blocker, $\alpha$-dendrotoxin.

$\alpha$-DTX was applied by either bath perfusion (at $1 \mu \mathrm{M}$ ) or puffer near the soma (at $2 \mu \mathrm{M}$ ); identical results were obtained for each. As for 4-AP, 1-2 $\mu \mathrm{M} \alpha$-DTX increased excitability in all neurons tested (Fig. 2) without affecting either the resting potential $(-72.5 \pm 1.0 \mathrm{mV}$ in control, $-73.1 \pm 1.0 \mathrm{mV}$ in toxin; $n=4 ; p>$ 0.28 , paired $t$ test) or the input resistance $(35.6 \pm 4.8 \mathrm{M} \Omega$ in control, $37.0 \pm 3.4 \mathrm{M} \Omega$ in toxin; $p>0.45)$. The toxin reduced the mean current required to first evoke an $\mathrm{AP}(283 \pm 40 \mathrm{pA}$ in control, $153 \pm 16 \mathrm{pA}$ in $\alpha$-DTX; $n=4 ; p<0.01$ ) (Fig. $2 B$ ) and increased the firing rate of APs during a 500 pA current step (Fig. $2 C$ ). Thus, $1-2 \mu \mathrm{M} \alpha$-DTX appeared to act like $100 \mu \mathrm{M} 4-\mathrm{AP}$ in enhancing the excitability of these neurons.

\section{Effects of 4-AP and $\alpha$-DTX on individual action potentials}

To further compare the effects of 4-AP and $\alpha$-DTX, the properties of individual APs were measured (Fig. 3). Both 4-AP and $\alpha$-DTX hyperpolarized by $4-8 \mathrm{mV}$ the firing threshold for APs (Fig. $3 A$, dashed lines, $B$ ), an effect that accounts for the reduced current needed to fire APs after drug perfusion (Figs. $1 B, 2 B$ ). In contrast, the two drugs differed in their effect on the AP halfwidth: $100 \mu \mathrm{M}$ 4-AP significantly broadened (by $0.15-0.59 \mathrm{msec}$ on average, depending on spike number) all but the first AP in the train, whereas $2 \mu \mathrm{M} \alpha$-DTX had no effect on half-width (Fig. $3 C$ ) ( $p<0.02$ for all except the first AP in 4-AP; $p>0.37$ for all APs in $\alpha$-DTX; $n=5$ cells). Finally, the afterhyperpolarization after each AP was not significantly affected by either 4-AP or $\alpha$-DTX $(-62.0 \pm 0.2 \mathrm{mV}$ in control, $-61.6 \pm 0.1 \mathrm{mV}$ in $4-\mathrm{AP},-63.6 \pm$ $0.2 \mathrm{mV}$ in $\alpha$-DTX; $p>0.05 ; n=5$ cells).

These results suggest that $100 \mu \mathrm{M} 4$-AP and $2 \mu \mathrm{M} \alpha$-DTX act in a similar, but not identical, manner to increase the excitability of large layer 5 cortical pyramidal neurons. The different effects on AP half-width may reflect nonspecific actions of 4-AP on the A-current (Storm, 1993). Therefore, the remainder of our experiments used only the more selective $I_{\mathrm{D}}$ blocker, $\alpha$-DTX.

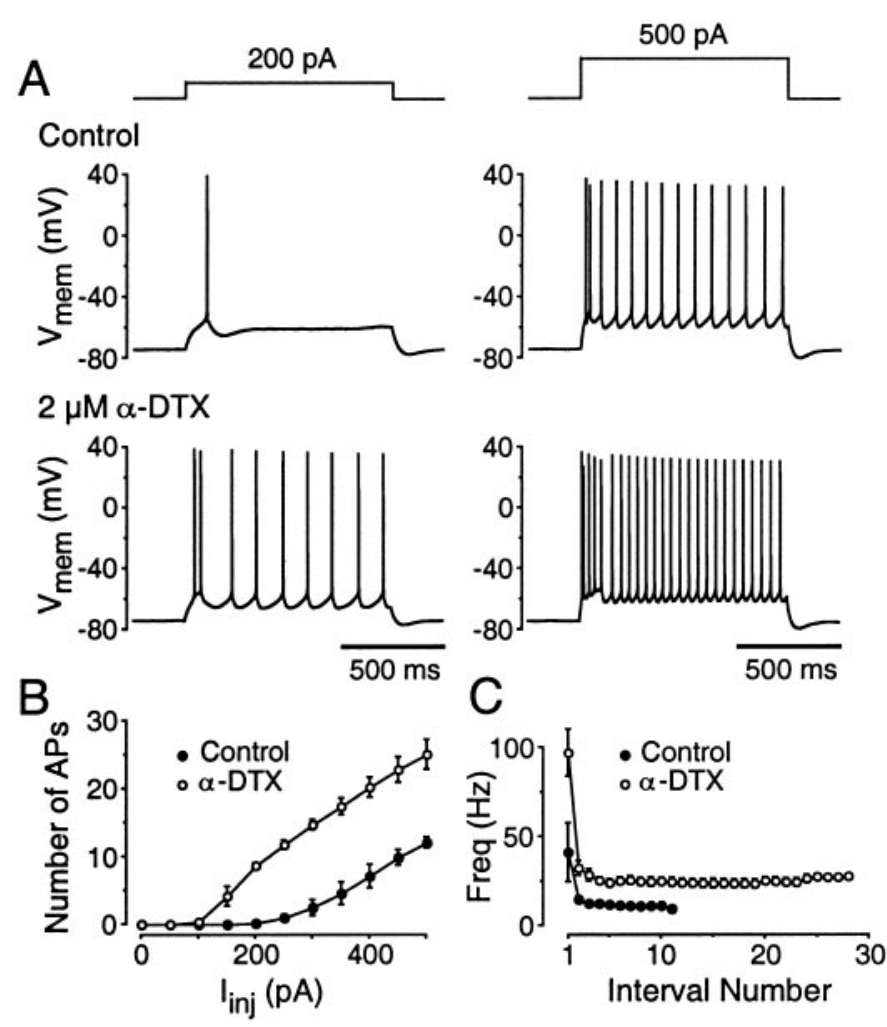

Figure 2. Bath or puffer application of 1-2 $\mu \mathrm{M} \alpha$-dendrotoxin $(\alpha-D T X)$ increases excitability, like $100 \mu \mathrm{M}$ 4-AP. $A$, Data recorded in the same neuron before (top) and after (bottom) puffing $2 \mu \mathrm{M} \alpha$-DTX near the soma. $B, C$, Summary plots like those in Figure $1(\mathbf{O}$, Control; $\bigcirc, \alpha-D T X$; $n=4$ cells; \pm SEM). Like 4 -AP, $\alpha$-DTX reduces the current required to fire APs and increases AP firing rate.

\section{$\alpha$-DTX partially inhibits a $\mathrm{K}^{+}$current in nucleated outside-out patches}

Evidence presented later in this paper suggests that $\alpha$-DTXsensitive $\mathrm{K}^{+}$channels are located on or near the soma. Accordingly, we used nucleated outside-out patches pulled from the soma to look for this current.

Nucleated patches were voltage clamped at $-67 \mathrm{mV}$, stepped to $-117 \mathrm{mV}$ for $500 \mathrm{msec}$ to remove resting inactivation of all potassium currents (Bekkers, 2000a), and then stepped to a test potential of $+3 \mathrm{mV}$. This elicited a brief inward $\mathrm{Na}^{+}$current followed by a slow outward $\mathrm{K}^{+}$current (Fig. $4 A$, insets) (leak and capacitance currents subtracted). Figure $4 A$ plots the amplitudes of both $\mathrm{Na}^{+}$and $\mathrm{K}^{+}$currents versus time for one experiment. After a baseline period, $2 \mu \mathrm{M} \alpha$-DTX was puffed onto the patch (Fig. 4A, bar), causing a small reduction in the $\mathrm{K}^{+}$current (Fig. $4 A$, ). The puffer solution also contained $0.5 \mu \mathrm{M}$ TTX as a positive control; complete blockade of the $\mathrm{Na}^{+}$current (Fig. $4 A$, 口) confirmed that the toxins were fully bathing the patch. Control experiments established that puffer solution without toxins had no effect. Thus, in this patch, $2 \mu \mathrm{M} \alpha$-DTX blocked a small ( $\sim 90$ pA) outward current (unlabeled trace in top inset).

The averaged, normalized time course plot from eight nucleated patches is shown in Figure $4 B . \alpha$-DTX $(2 \mu \mathrm{M})$ caused a mean inhibition of the outward current of $6 \pm 3 \%(\bullet)$ compared with the average of amplitudes before and after toxin application. Thus, nucleated outside-out patches do contain an $\alpha$-DTXsensitive current, but it is a minor component of the total $\mathrm{K}^{+}$ current. 

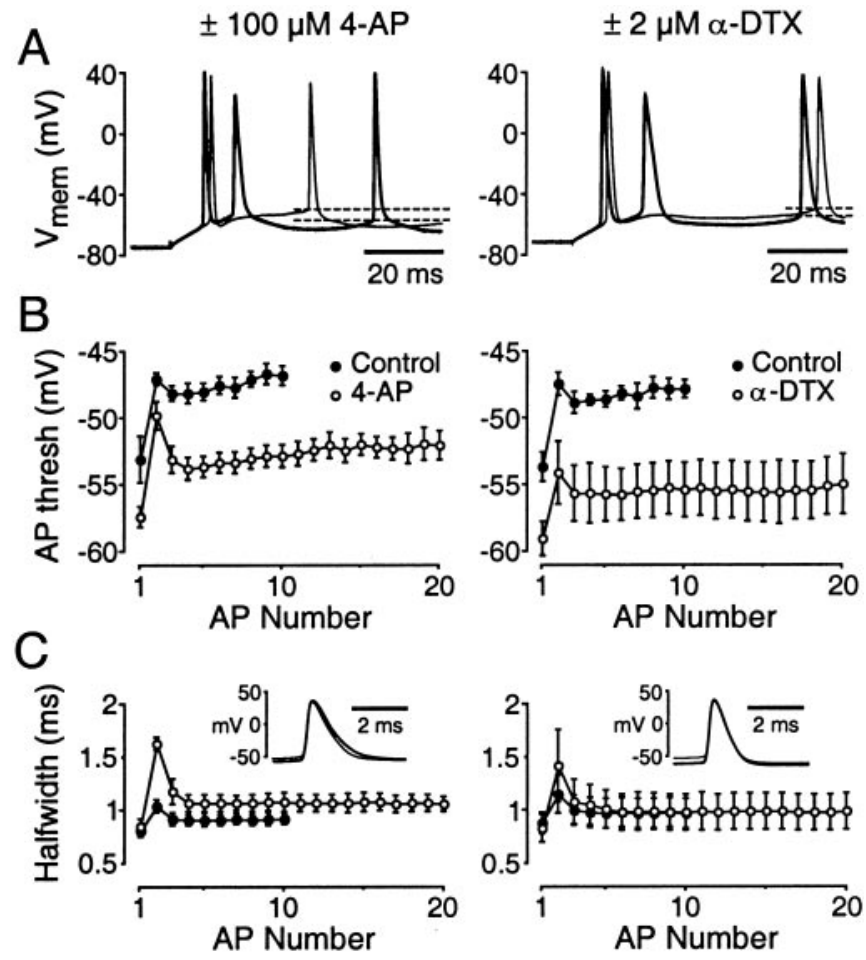

Figure 3. 4-AP (left panels) and $\alpha$-DTX (right panels) both hyperpolarize the firing threshold for APs, but differ in their effects on AP half-width. $A$, APs near the start of a 1-sec-long $500 \mathrm{pA}$ current step, recorded before (thin line) and after (thick line) application of $100 \mu \mathrm{M} 4$-AP (left) or $2 \mu \mathrm{M}$ $\alpha$-DTX (right). Each panel is from a different neuron. Horizontal dashed lines indicate the firing thresholds for later APs with and without drugs. $B$, Mean firing threshold for each AP in a train during a 1-sec-long $500 \mathrm{pA}$ current step versus the AP number. - , Control; O, $100 \mu \mathrm{M}$ 4-AP (left panel; $n=5$ cells; \pm SEM) or $2 \mu \mathrm{M} \alpha$-DTX (right panel; $n=4$ cells; \pm SEM). Both 4 -AP and $\alpha$-DTX hyperpolarize the firing threshold throughout the train. $C$, Mean half-width for each AP in the train, for the same data set as in B. 4-AP significantly increases the half-width of all but the first AP (left panel), whereas $\alpha$-DTX has no effect (right panel). Insets show the sixth AP in an illustrative train, recorded in control (thin line) or in drug solution (thick line).

\section{Activation properties of the $\alpha$-DTX-sensitive current in nucleated patches}

Because the $\alpha$-DTX-sensitive current is small, it was not practical to obtain complete activation families of this current by subtracting records obtained in the same nucleated patch before and after application of $\alpha$-DTX, because of rundown and other instabilities. Instead, we compared averaged, normalized activation plots for different patches in either the presence or absence of $\alpha$-DTX; any differences between them would reflect the $\alpha$-DTX-sensitive component.

We first tried this strategy in normal bath solution. Activation families of $\mathrm{K}^{+}$currents were recorded in the presence or absence of $\alpha$-DTX ( $2 \mu \mathrm{M}$ applied by puffer), and their amplitudes were measured over a window 100-150 msec after the start of the test pulse. This is on the plateau of the $\alpha$-DTX-sensitive current (Fig. $4 A$, inset) and avoids the fast A-current that is present in these patches (Bekkers, 2000a). After conversion to conductance, activation plots were fitted to the Boltzmann equation (Materials and Methods). It was found that the fit parameters in the two conditions were not significantly different $(p>0.12$, unpaired $t$ test; $n=7$ cells in each condition). This result may arise if the
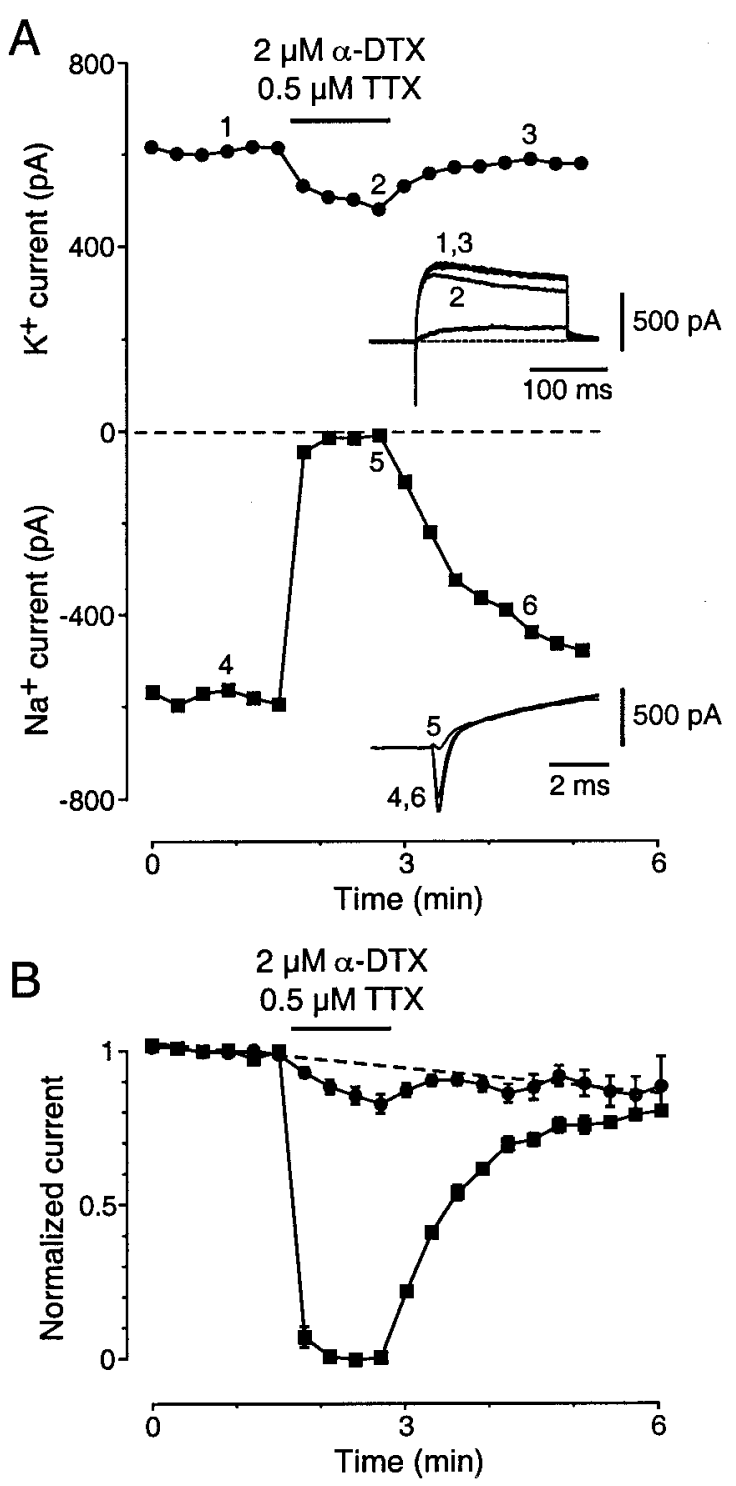

Figure 4. Two micromolar $\alpha$-DTX has a small inhibitory effect on $\mathrm{K}^{+}$ current recorded in voltage-clamped nucleated outside-out patches. $A$, Amplitudes of outward $\mathrm{K}^{+}$current $(t o p, 0)$ and inward $\mathrm{Na}^{+}$current $($ bottom, $\mathbf{\square})$ measured simultaneously in a nucleated patch during voltageclamp steps from $-117 \mathrm{mV}$ to $+3 \mathrm{mV}$, plotted against time during the experiment. $\mathrm{K}^{+}$current amplitude was averaged over a window $100-150$ msec after the step onset, to avoid A-current; $\mathrm{Na}^{+}$current was measured at the peak. Puffer application of $2 \mu \mathrm{M} \alpha$-DTX (horizontal bar) caused a small inhibition of the $\mathrm{K}^{+}$current, whereas $0.5 \mu \mathrm{M}$ tetrodotoxin $(T T X)$ included in the puffer solution fully blocked the $\mathrm{Na}^{+}$current, confirming that the toxins were bathing the patch. Insets show, on slow (top) and fast (bottom) time bases, the currents measured at the numbered time points. Unlabeled trace in the top inset is the $\alpha$-DTX-sensitive current, obtained by subtraction. $B$, Mean normalized $\mathrm{K}^{+}$current $(\bullet)$ and $\mathrm{Na}^{+}$current (ם) measured in 11 experiments of this sort. The dashed line is drawn by eye to emphasize the small mean inhibition produced by $2 \mu \mathrm{M} \alpha$-DTX: $6 \%$ on average.

$\alpha$-DTX-sensitive current is too small to reliably measure against a large background of the delayed rectifier, $I_{\mathrm{K}}$.

To explore this possibility, we repeated the experiment in bath solution containing $30 \mathrm{~mm}$ TEA to partially block $I_{\mathrm{K}}$ and so increase the relative size of $\alpha$-DTX-sensitive current. [The latter current is not affected by TEA (Storm, 1988.)] It was first confirmed that $2 \mu \mathrm{M} \alpha$-DTX reversibly blocked a $\mathrm{K}^{+}$current in 


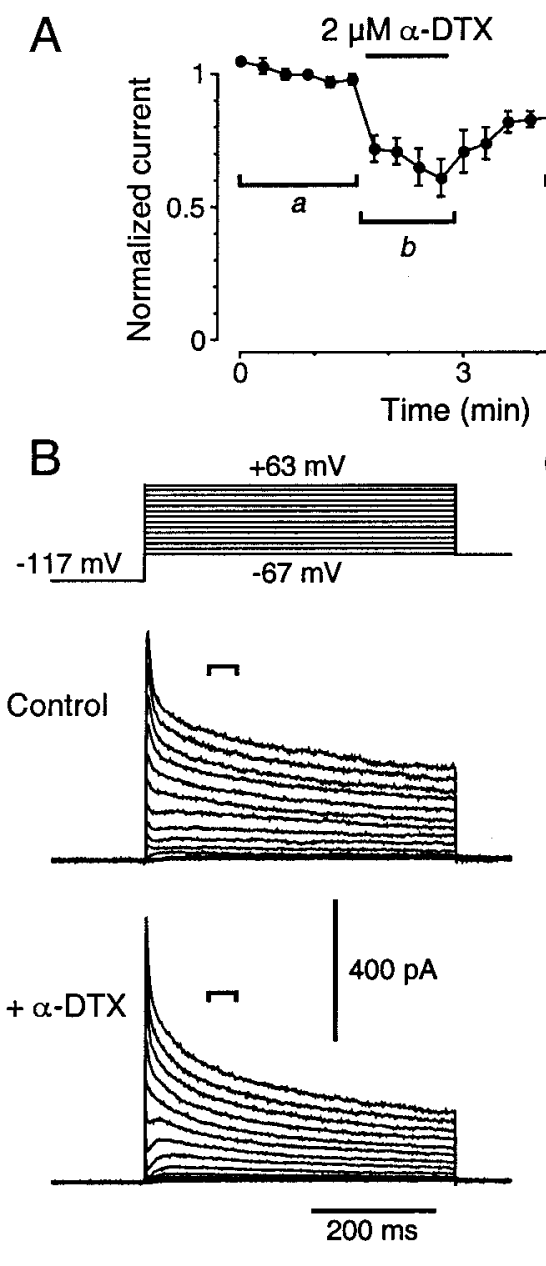

nucleated patches in TEA solution (Fig. 5A). The mean amplitude of the current blocked by $\alpha$-DTX in TEA-containing bath solution (35 $\pm 7 \mathrm{pA} ; n=6$ patches) was similar to that in normal bath solution ( $40 \pm 15 \mathrm{pA} ; n=8$ patches). However, because $I_{\mathrm{K}}$ was reduced by $\sim 85 \%$ in $30 \mathrm{~mm}$ TEA (Korngreen and Sakmann, 2000 ), the percentage block by $\alpha$-DTX, relative to the total amount of slow $\mathrm{K}^{+}$current, was much larger in TEA [28 $\pm 7 \%$; $n=6$ (Fig. $5 A$ ); cf. $6 \%$ in normal bath solution (Fig. $4 B$ )]. Thus, TEA emphasized the $\alpha$-DTX-sensitive current and facilitated measurement of its properties.

Activation families in $30 \mathrm{~mm}$ TEA were measured in separate patches in the presence or absence of $2 \mu \mathrm{M} \alpha$-DTX (Fig. $5 B$ ). The averaged, normalized activation plot in each condition was fitted to the Boltzmann equation (Fig. $5 C$ ). The activation plot was significantly shifted to the right by addition of $\alpha$-DTX $\left(V_{1 / 2}=4.8\right.$ $\mathrm{mV}, k=25.7 \mathrm{mV}$ in control, $n=7$ patches; $V_{1 / 2}=22.1 \mathrm{mV}, k=$ $26.0 \mathrm{mV}$ in $\alpha$-DTX, $n=5$ patches; $p<0.01$, unpaired $t$ test). The activation plot for $\alpha$-DTX-sensitive current was calculated by subtracting the " $+\alpha$-DTX" activation data from the " $-\alpha$-DTX" data, after scaling down the amplitude of the former by $28 \%$ (the mean inhibition produced by $2 \mu \mathrm{M} \alpha$-DTX in TEA) (Fig. 5A). The result of this calculation, after renormalization, is shown in Figure $5 D$. Fit of the Boltzmann equation to this plot gave $V_{1 / 2}=$ $-22.4 \mathrm{mV}, k=18.9 \mathrm{mV}$ (Fig. $5 D$, continuous curve). This is similar to the peak activation plot for $I_{\mathrm{K}}$ measured in the same cells (Fig. 5D, dashed curve) (from Bekkers, 2000a).

Note that the activation plot shown in Figure $5 C(+\alpha$-DTX,
Figure 5. Bath application of TEA reduces the amount of the delayed rectifier current $\left(I_{\mathrm{K}}\right)$ in nucleated patches, facilitating measurement of the activation properties of $\alpha$-DTX-sensitive current. $A$, Averaged, normalized amplitudes of $\mathrm{K}^{+}$current measured in nucleated patches bathed in external solution containing $30 \mathrm{~mm}$ TEA plus $0.4 \mu \mathrm{M}$ TTX, plotted against time during the experiment. Currents were evoked by voltage-clamp steps from -117 to $+43 \mathrm{mV}$, and their amplitudes were measured by averaging over a window $100-150 \mathrm{msec}$ after the start of the step. Puffer application of TEA-TTX solution plus $2 \mu \mathrm{M} \alpha$-DTX (horizontal bar) reversibly inhibited the $\mathrm{K}^{+}$current by $28 \%$ on average. Inset shows typical currents recorded in one patch, averaged during the control and wash periods (trace $a$ ) and during the period of toxin application (trace $b$ ). Unlabeled trace is the subtraction of trace $b$ from $a$, the $\alpha$-DTX-sensitive current. $B$, Families of voltageclamped $\mathrm{K}^{+}$currents recorded in nucleated patches in TEA-TTX bath solution in the absence (top) and presence (bottom) of $2 \mu \mathrm{M} \alpha$-DTX, applied by puffer. The pulse protocol is shown at the top. Square brackets over the current traces indicate the window over which the amplitude was measured for the activation plots (100-150 msec after the start of the test pulse). Note that the recordings were obtained from different patches. $C$, Averaged, normalized activation plots in the absence $(\boldsymbol{Q} ; n=7$ patches $)$ and presence ( $\bigcirc ; n=5$ patches) of $2 \mu \mathrm{M} \alpha$-DTX, all in TEA-TTX solution. Superimposed smooth curves are the results of fits of the Boltzmann function with the indicated fit parameters. $D$, Activation plot for the $\alpha$-DTXsensitive current, obtained by scaling down the $+\alpha$-DTX data in $C$ by $28 \%$, subtracting this from the $-\alpha$-DTX data, and renormalizing the result. The superimposed continuous curve is a Boltzmann fit to the points, giving the indicated fit parameters. The dashed curve is the mean activation plot for $I_{\mathrm{K}}$ measured in nucleated patches from the same neurons, reported in Bekkers (2000a). 


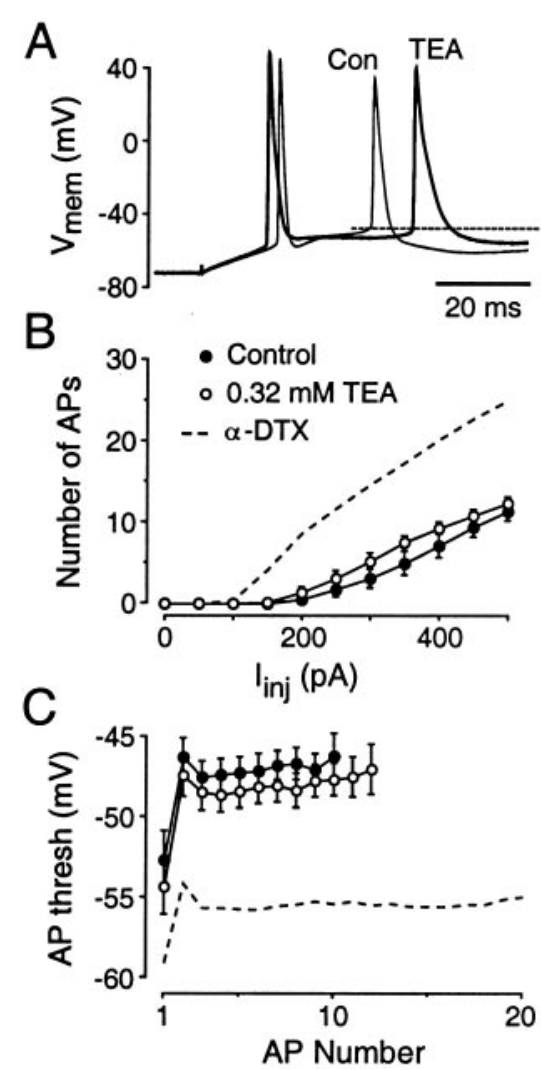

Figure 6. $\alpha$-DTX-sensitive channels are functionally different from TEA-sensitive $I_{\mathrm{K}}$ channels. $A$, APs near the start of a $500 \mathrm{pA}$ current step, recorded in the same neuron before (Con, thin line) and after (TEA, thick line) perfusion of bath solution containing $0.32 \mathrm{~mm}$ TEA. This concentration of TEA blocks $\sim 6 \%$ of $I_{\mathrm{K}}$, which is the same percentage of the total slow $\mathrm{K}^{+}$current as is blocked by $2 \mu \mathrm{M} \alpha$-DTX. The horizontal dashed line indicates that the AP firing threshold is little affected by TEA (see $C$ ); however, spike broadening is clearly apparent in TEA, probably because of its inhibition of the fast $\mathrm{Ca}^{2+}$-activated $\mathrm{K}^{+}$current, $I_{\mathrm{C}} \cdot B$, Mean number of APs elicited by 1 -sec-long current steps to the indicated values (๑, Control; $\bigcirc, T E A ; n=7$ cells). TEA $(0.32 \mathrm{mM})$ has only a weak effect on the current required to fire APs. For comparison, the dashed line shows the effect of $2 \mu \mathrm{M} \alpha$-DTX, from Figure $2 B$. C, Mean firing threshold for each AP in a train during a 1-sec-long $500 \mathrm{pA}$ current step, plotted against the AP number. Same symbols and data set as in $B$. For comparison, the dashed line shows the effect of $\alpha$-DTX, from Figure $3 B$. Unlike $\alpha$-DTX, TEA has no significant effect on the firing threshold.

TEA did prolong AP half-widths $(1.09 \pm 0.02 \mathrm{msec}$ in control, $1.46 \pm 0.04 \mathrm{msec}$ in TEA; $p>0.1$ ) (Fig. $6 A$ ), contrasting with $\alpha$-DTX, which had no effect on half-widths (Fig. 3C). Similar results were obtained for another cell to which 1.1 mM TEA was applied (sufficient to block $\sim 18 \%$ of $I_{\mathrm{K}}$ ).

In summary, both $\alpha$-DTX and low concentrations of TEA blocked part of a delayed rectifier-like $\mathrm{K}^{+}$current in these neurons, yet these drugs had very different effects on the behavior of APs. These results strongly suggest that TEA-sensitive $I_{\mathrm{K}}$ channels and $\alpha$-DTX-sensitive channels are functionally distinct. A possible explanation is that the two channel types differ subtly in their kinetics or voltage dependence (Fig. 5D). This was hard to study in detail, given the small size of the $\alpha$-DTX-sensitive currents and the difficulties of the pharmacological method for separating them. We therefore turned to another possibility and asked whether these functional differences might reflect differences in channel distributions.

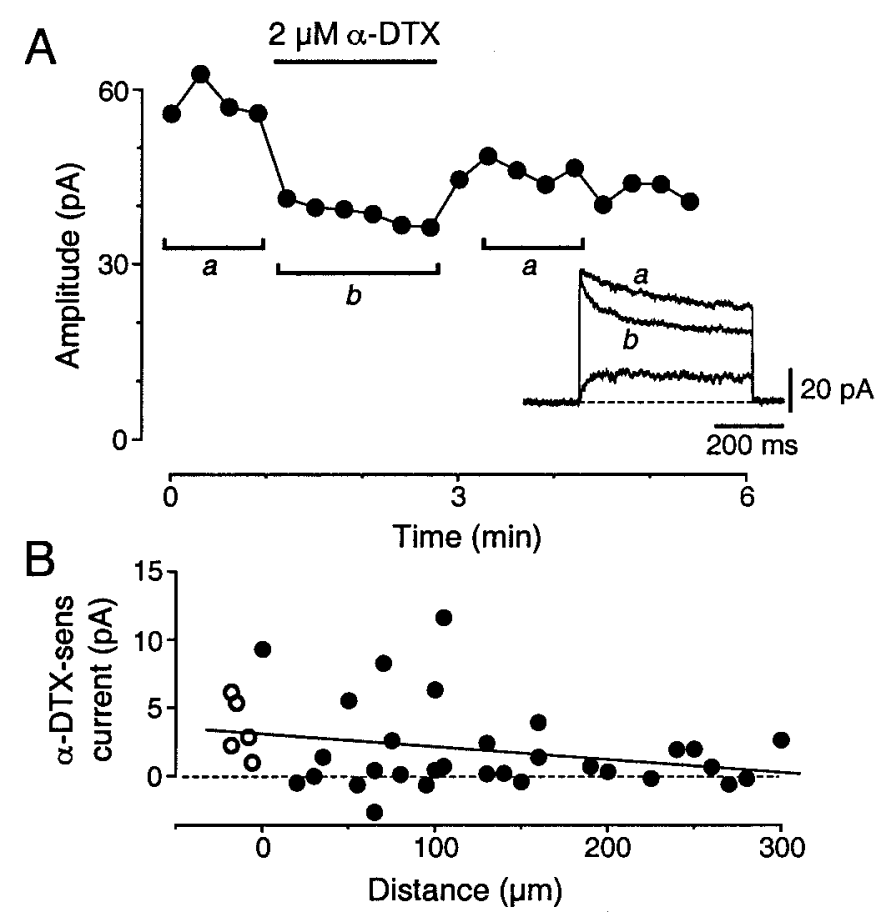

Figure 7. $\quad \alpha$-DTX-sensitive channels, assayed in conventional outside-out patches, are concentrated near the soma. $A$, Amplitude of $\mathrm{K}^{+}$current measured during a voltage-clamp step from a prepulse $(-117 \mathrm{mV}$ for 500 $\mathrm{msec}$ ) to a test pulse of $+43 \mathrm{mV}$ (repeated 5 times and averaged), plotted against time during the experiment. Amplitude was averaged over a window $100-150 \mathrm{msec}$ after the step onset. $\alpha$-DTX $(2 \mu \mathrm{M})$ was applied by puffer (horizontal bar). Labeled traces in the inset are averages of the currents enclosed by square brackets in the time course plot; the unlabeled trace is the subtraction of trace $b$ from $a$. This patch was pulled from the primary apical dendrite $105 \mu \mathrm{m}$ from the soma. $B$, Amplitude of $\alpha$-DTX-sensitive current (each point obtained from a separate outsideout patch using the averaged-subtraction method described in $A$ ) plotted against the distance from the soma that the patch was pulled. Patches were from either the axon $(\bigcirc)$ or the primary apical dendrite $(0)$. The continuous straight line is given by $I=3.2-0.009 d$, where $I$ is the mean amplitude of the $\alpha$-DTX-sensitive current in picoamperes, and $d$ is the distance from the soma in micrometers.

\section{$\alpha$-DTX-sensitive channels tend to be concentrated near the soma}

In three cells, puffer application of $2 \mu \mathrm{M} \alpha$-DTX to the primary apical dendrite $(\sim 100 \mu \mathrm{m}$ from the soma) had little effect on neuronal excitability (data not shown). In the same cells, puffing $\alpha$-DTX close to the soma increased excitability as usual (Fig. 2). In a different experiment, bath perfusion of $100 \mu \mathrm{M} 4$-AP caused the usual increase in excitability in a neuron in which the primary apical dendrite had been amputated $160 \mu \mathrm{m}$ from the soma [using the method described in Bekkers (2000c)]. Both of these experiments suggest that distal membrane does not contain a high density of $\alpha$-DTX-sensitive current, or if it does, this current contributes little to the spiking behavior initiated by somatic current injections. To further examine this issue, the axodendritic density of $\alpha$-DTX-sensitive channels was mapped.

Conventional outside-out patches were pulled from known locations on the axon and primary apical dendrite of large layer 5 pyramidal neurons. For each patch, a time course plot was acquired before, during, and after application of $2 \mu \mathrm{M} \alpha$-DTX using a puffer (Fig. 7A). The amplitude of $\alpha$-DTX-sensitive current was estimated by subtracting averaged currents obtained during toxin 
application from the averages of currents before and after the toxin (Fig. $7 A$, inset).

The amplitude of toxin-sensitive current in each patch was plotted against the distance from the soma to the point on the axon or dendrite from which the patch was pulled (Fig. $7 B$ ). The mean amplitude of the $\alpha$-DTX-sensitive current declined with distance along the dendrite from the soma (slope $-0.9 \mathrm{pA} / 100$ $\mu \mathrm{m})$ (Fig. $7 B$, fitted straight line). The mean current was $3.6 \pm 1$ $\mathrm{pA}$ in the axon ( $n=5$ patches), $2.2 \pm 1 \mathrm{pA}(n=14)$ in the proximal $100 \mu \mathrm{m}$ of the dendrite, and $0.9 \pm 0.4 \mathrm{pA}(n=8)$ in the dendrite 200-300 $\mu \mathrm{m}$ from the soma. Thus, the toxin-sensitive current is small but shows a tendency to concentrate in the axon and proximal apical dendrite. This contrasts with delayed rectifier potassium current, which is both larger and more uniformly distributed along the primary apical dendrite of these neurons $(13.4 \pm 2.0 \mathrm{pA}$ over $0-100 \mu \mathrm{m}, 10.5 \pm 2.1 \mathrm{pA}$ over $200-300 \mu \mathrm{m})$ (Bekkers, 2000b).

\section{DISCUSSION}

In this paper we have shown that $\alpha$-DTX-sensitive $I_{\mathrm{D}}$-like potassium channels are present on large pyramidal neurons in layer 5 of rat neocortex, albeit at a relatively low density. Despite their scarcity, blockade of these channels had a powerful effect on the excitability of the neurons. Addition of $\alpha$-DTX hyperpolarized the firing threshold for APs by $\sim 5 \mathrm{mV}$ (Fig. 3) and roughly doubled the firing frequency of APs during prolonged $500 \mathrm{pA}$ current injections (Fig. 2). By assaying the amount of $\alpha$-DTXsensitive current present in outside-out patches pulled from the axon and primary apical dendrite, we showed that these $I_{\mathrm{D}}$-like channels tended to be concentrated close to the soma (Fig. 7). Given that the usual site of AP initiation is in the axon of these neurons (Stuart et al., 1997a), $\alpha$-DTX-sensitive channels are strategically located for influencing neuronal excitability.

$I_{\mathrm{D}}$ was first described by Storm (1988) in hippocampal CA1 pyramidal neurons. It was distinguished by its slow inactivation, sensitivity to $40 \mu \mathrm{M} 4-\mathrm{AP}$, and ability to delay the onset of AP firing during long current steps. A more recent criterion is its sensitivity to $\alpha$-DTX, which has been shown to block the same slowly inactivating current as 50-100 $\mu \mathrm{M}$ 4-AP in hippocampal (Wu and Barish, 1992; Golding et al., 1999) and cortical neurons (Foehring and Surmeier, 1993; Locke and Nerbonne, 1997). Even within this class of $4-\mathrm{AP} / \alpha$-DTX-sensitive currents there is a marked diversity in biophysical properties (Wu and Barish, 1992; Foehring and Surmeier, 1993; Albert and Nerbonne, 1995; Bossu et al., 1996; Lüthi et al., 1996; Massengill et al., 1997; Budde and White, 1998). Thus, $I_{\mathrm{D}}$ has been defined as a dendrotoxinsensitive voltage-sensitive current with variable kinetics and voltage dependence that is also sensitive to low concentrations of 4-AP (Coetzee et al., 1999). It probably encompasses various subunit combinations, most likely Kv1.2 with other subunits (Coetzee et al., 1999).

Given that 4-AP also blocks the A-current (Storm, 1993), we preferred to use $\alpha$-DTX as the defining antagonist because of its presumed greater specificity. Indeed, subtle pharmacological differences between $100 \mu \mathrm{M} 4$-AP and $2 \mu \mathrm{M} \alpha$-DTX are apparent from their different effects on AP half-width (Fig. 3C). This may be attributable to partial blockade of the A-current by micromolar 4-AP, as has been reported (Storm, 1987, 1988). Alternatively, it is possible that $I_{\mathrm{D}}$ in these neurons is inhibited differently by 4-AP and $\alpha$-DTX, or that several variants of $I_{\mathrm{D}}$ are present and are differentially inhibited by these compounds. Notwithstanding these ambiguities, we use the term " $I_{\mathrm{D}}$ " as a convenient shorthand for the current blocked by $\alpha$-DTX.

The small size of $I_{\mathrm{D}}$ in nucleated patches from large layer 5 pyramids $\left(\sim 6 \%\right.$ of total slow $\mathrm{K}^{+}$current in normal external solution) (Fig. $4 B$ ) may explain why we did not detect $I_{\mathrm{D}}$ in earlier studies on these neurons (Bekkers, 2000a), although others have reported small effects of DTX-I (Korngreen and Sakmann, 2000) and micromolar concentrations of 4-AP (Albert and Nerbonne, 1995) on this cell type. Our result agrees with immunocytochemical staining showing a relative paucity of Kv1.2 on the somata of these neurons (Sheng et al., 1994). On the other hand, Sheng et al. (1994) found a high density of Kv1.2 along the length of the apical dendrites of cortical neurons. It was surprising, therefore, to discover that the dendritic density of $I_{\mathrm{D}}$, assayed in outside-out patches, was not markedly greater than on the soma and, indeed, tended to decrease with distance from the soma (Fig. $7 B$ ). The discrepancy might be explained by the absence from the dendrites of an additional subunit(s) that must coassemble with Kv1.2 to produce a functional channel in these cells (cf. Grissmer et al., 1994). Alternatively, developmental factors may be important: Sheng et al. (1994) used adult rats, whereas our experiments used 14- to 21-d-old animals. Upregulation of Kv1 mRNA in rat brain beyond the first 2 postnatal weeks has been reported (Swanson et al., 1990).

The voltage-dependence of activation of $\alpha$-DTX-sensitive current is similar to that of the delayed rectifier current, $I_{\mathrm{K}}$, which is the dominant slow $\mathrm{K}^{+}$current in these neurons (Fig. 5D) (Bekkers, 2000a). Both start to activate at around $-60 \mathrm{mV}$, negative to the threshold for AP firing (approximately $-54 \mathrm{mV}$ in control conditions) (Fig. $3 B$ ). The activation of $I_{\mathrm{D}}$ at subthreshold potentials can also be inferred from the observation that the threshold for the first AP in a train is significantly hyperpolarized by $\alpha$-DTX (Fig. $3 B$ ); that is, $\alpha$-DTX has an effect on APs before the membrane potential has depolarized for the first time above AP threshold. After activation of $I_{\mathrm{D}}$, its slow inactivation kinetics ensures that it never fully turns off during the train, suppressing excitability and lengthening the interspike interval (Erisir et al., 1999). Blockade of $I_{D}$ thus enhances excitability and firing frequency. Interestingly, this enhanced excitability is manifested differently in regular spiking pyramidal neurons in subiculum and CA1 of rat hippocampus: blockade of $I_{\mathrm{D}}$ converts these neurons into a distinct burst-firing mode (Staff et al., 2000), in contrast to our results for the majority of large layer 5 pyramidal neurons, which showed only an increased frequency of regular firing (Fig. 2C).

Despite the similarity of $I_{\mathrm{D}}$ to $I_{\mathrm{K}}$, blockade of $I_{\mathrm{D}}$ (with $\alpha$-DTX) and blockade of a similar amount of $I_{\mathrm{K}}$ (with TEA) had dissimilar effects on excitability. One difference was that TEA significantly broadened the APs, whereas $\alpha$-DTX did not. This is most easily explained by the nonspecific (for present purposes) inhibitory effect of TEA on the fast calcium-activated $\mathrm{K}^{+}$current, $I_{\mathrm{C}}$. This inhibition is well known to produce spike broadening (Storm, 1987; Schwindt et al., 1988). The other difference was that TEA had no effect on the threshold for AP firing, in contrast to $\alpha$-DTX (Fig. $6 C$; compare Fig. $3 B$ ). It is possible that subtle differences in the voltage-dependent properties of $I_{\mathrm{D}}$ and $I_{\mathrm{K}}$ can explain this. For example, the $V_{1 / 2}$ for peak activation of $I_{\mathrm{D}}$ is slightly hyperpolarized from that for $I_{\mathrm{K}}[-22.4 \mathrm{mV}$, cf. $-17.0 \mathrm{mV}$ (Fig. $5 D$ and Bekkers, 2000a)]. This will emphasize the effect of $I_{\mathrm{D}}$ near spike threshold, which is a voltage range in which small conductance changes can have large effects on the trajectory of the membrane potential. 
Activation kinetics may also be an important difference between $I_{\mathrm{D}}$ and $I_{\mathrm{K}}$. In other cell types, $I_{\mathrm{D}}$ has been reported to activate more rapidly than $I_{\mathrm{K}}$ (Wu and Barish, 1992; Bossu et al., 1996; Locke and Nerbonne, 1997). However, estimates of the activation kinetics of subtraction-isolated currents are very sensitive to rundown, and none of the above studies used bracketing, as we did, to minimize these errors. In our data, $I_{\mathrm{D}}$ exhibited both slow (Figs. $4 A, 7 A$ ) and fast [followed by slow (Fig. $5 A$ )] activation kinetics. This variability may be intrinsic to $I_{\mathrm{D}}$, or it may reflect difficulties with the pharmacological subtraction method. If the activation of $I_{\mathrm{D}}$ is indeed faster than that of $I_{\mathrm{K}}$, this may allow $I_{\mathrm{D}}$ to make a larger contribution during the brief depolarization produced by an AP.

Functional differences between $I_{\mathrm{K}}$ and $I_{\mathrm{D}}$ may also stem from their contrasting dendritic distributions. Whereas $I_{\mathrm{K}}$ is uniformly distributed (Bekkers, 2000b), $I_{\mathrm{D}}$ tends to be concentrated near the soma (Fig. $7 B$ ) (although it remains possible that $I_{\mathrm{D}}$ density in the basal dendrites, where we could not measure, is high). This may adapt $I_{\mathrm{D}}$ to the role of modulating spike threshold in the axon. Such a role could be further enriched if $I_{\mathrm{D}}$ is subject to neuromodulation. Indeed, activation of metabotropic glutamate receptors has recently been reported to accelerate the inactivation of $I_{\mathrm{D}}$ in CA1 pyramidal neurons, increasing neuronal excitability (Wu and Barish, 1999).

In summary, we have shown that $I_{\mathrm{D}}$ is present, although at low density, in large layer 5 pyramidal neurons of the rat neocortex. The strategic location of $I_{\mathrm{D}}$ near the site of AP initiation in the axon ensures that it will have a powerful effect on the regulation of neuronal excitability and thus on the coupling between synaptic input and AP output.

\section{REFERENCES}

Albert JL, Nerbonne JM (1995) Calcium-independent depolarizationactivated potassium currents in superior colliculus-projecting rat visual cortical neurons. J Neurophysiol 73:2163-2178.

Bekkers JM (2000a) Properties of voltage-gated potassium currents in nucleated patches from large Layer 5 cortical pyramidal neurons of the rat. J Physiol (Lond) 525:593-609.

Bekkers JM (2000b) Distribution and activation of voltage-gated potassium channels in cell-attached and outside-out patches from large Layer 5 cortical pyramidal neurons of the rat. J Physiol (Lond) 525:611-620.

Bekkers JM (2000c) Distribution of slow AHP channels on hippocampal CA1 pyramidal neurons. J Neurophysiol 83:1756-1759.

Berger T, Larkum ME, Lüscher H-R (2001) High $\mathrm{I}_{\mathrm{h}}$ channel density in the distal apical dendrite of Layer $\mathrm{V}$ pyramidal cells increases bidirectional attenuation of EPSPs. J Neurophysiol 85:855-868.

Bossu J-L, Capogna M, Debanne D, McKinney RA, Gähwiler BH (1996) Somatic voltage-gated potassium currents of rat hippocampal pyramidal cells in organotypic slice cultures. J Physiol (Lond) 495:367-381.

Budde T, White JA (1998) The voltage-dependent conductances of rat neocortical layer I neurons. Eur J Neurosci 10:2309-2321.

Coetzee WA, Amarillo Y, Chiu J, Chow A, Lau D, McCormack T, Moreno H, Nadal MS, Ozaita A, Pountney D, Saganich M, Vega-Saenz de Miera E, Rudy B (1999) Molecular diversity of $\mathrm{K}^{+}$channels. Ann NY Acad Sci 868:233-285.

Erisir A, Lau D, Rudy B, Leonard CS (1999) Function of specific K ${ }^{+}$ channels in sustained high-frequency firing of fast-spiking neocortical interneurons. J Neurophysiol 82:2476-2489.

Foehring RC, Surmeier DJ (1993) Voltage-gated potassium currents in acutely dissociated rat cortical neurons. J Neurophysiol 70:51-63.

Golding NL, Jung H-y, Mickus T, Spruston N (1999) Dendritic calcium spike initiation and repolarization are controlled by distinct potassium channel subtypes in CA1 pyramidal neurons. J Neurosci 19:8789-8798.
Grissmer S, Nguyen AN, Aiyar J, Hanson DC, Mather RJ, Gutman GA, Karmilowicz MJ, Auperin DD, Chandy KG (1994) Pharmacological characterization of five cloned voltage-gated $\mathrm{K}^{+}$channels, types Kv1.1, $1.2,1.3,1.5$, and 3.1 , stably expressed in mammalian cell lines. Mol Pharmacol 45:1227-1234.

Häusser M, Spruston N, Stuart GJ (2000) Diversity and dynamics of dendritic signaling. Science 290:739-744.

Hille B (1992) Ionic channels of excitable membranes. Sunderland, MA: Sinauer.

Hoffman DA, Magee JC, Colbert CM, Johnston D (1997) $\mathrm{K}^{+}$channel regulation of signal propagation in dendrites of hippocampal pyramidal neurons. Nature 387:869-875.

Kasper EM, Larkman AU, Lübke J, Blakemore C (1994) Pyramidal neurons in Layer 5 of the rat visual cortex. II. Development of electrophysiological properties. J Comp Neurol 339:475-494.

Korngreen A, Sakmann B (2000) Voltage-gated $\mathrm{K}^{+}$channels in layer 5 neocortical pyramidal neurones from young rats: subtypes and gradients. J Physiol (Lond) 525:621-639.

Locke RE, Nerbonne JM (1997) Three kinetically distinct $\mathrm{Ca}^{2+}$ independent depolarization-activated $\mathrm{K}^{+}$currents in callosalprojecting rat visual cortical neurons. J Neurophysiol 78:2309-2320.

Lüthi A, Gähwiler BH, Gerber U (1996) A slowly inactivating potassium current in CA3 pyramidal cells of rat hippocampus in vitro. J Neurosci 16:586-594.

Martina M, Schultz JH, Ehmke H, Monyer H, Jonas P (1998) Functional and molecular differences between voltage-gated $\mathrm{K}^{+}$channels of fastspiking interneurons and pyramidal neurons of rat hippocampus. J Neurosci 18:8111-8125.

Massengill JL, Smith MA, Son DI, O'Dowd DK (1997) Differential expression of $K_{4 \mathrm{AP}}$ currents and Kv3.1 potassium channel transcripts in cortical neurons that develop distinct firing phenotypes. J Neurosci 17:3136-3147.

Schwindt PC, Spain WJ, Foehring RC, Stafstrom CE, Chubb MC, Crill WE (1988) Multiple potassium conductances and their functions in neurons from cat sensorimotor cortex in vitro. $J$ Neurophysiol 59:424-449.

Sheng M, Tsaur M-L, Jan YN, Jan LY (1994) Contrasting subcellular localization of the $\mathrm{Kv} 1.2 \mathrm{~K}^{+}$channel subunit in different neurons of rat brain. J Neurosci 14:2408-2417.

Staff NP, Jung H-Y, Thiagarajan T, Yao M, Spruston N (2000) Resting and active properties of pyramidal neurons in subiculum and CA1 of rat hippocampus. J Neurophysiol 84:2398-2408.

Storm JF (1987) Action potential repolarization and a fast afterhyperpolarization in rat hippocampal pyramidal cells. J Physiol (Lond) 385:733-759

Storm JF (1988) Temporal integration by a slowly inactivating $\mathrm{K}^{+}$current in hippocampal neurons. Nature 336:379-381.

Storm JF (1993) Functional diversity of $\mathrm{K}^{+}$currents in hippocampal pyramidal neurons. Semin Neurosci 5:79-92.

Stuart G, Schiller J, Sakmann B (1997a) Action potential initiation and propagation in rat neocortical pyramidal neurons. J Physiol (Lond) 505:617-632.

Stuart G, Spruston N, Sakmann B, Häusser M (1997b) Action potential initiation and backpropagation in neurons of the mammalian CNS. Trends Neurosci 20:125-131.

Stuart GJ, Sakmann B (1994) Active propagation of somatic action potentials into neocortical pyramidal cell dendrites. Nature 367:69-72.

Swanson R, Marshall J, Smith JS, Williams JB, Boyle MB, Folander K, Luneau CJ, Antanavage J, Oliva C, Buhrow SA, Bennett C, Stein RB, Kaczmarek LK (1990) Cloning and expression of cDNA and genomic clones encoding three delayed rectifier potassium channels in rat brain. Neuron 4:929-939.

Williams SR, Stuart GJ (1999) Mechanisms and consequences of action potential burst firing in rat neocortical pyramidal neurons. J Physiol (Lond) 521:467-482.

Williams SR, Stuart GJ (2000) Site independence of EPSP time course is mediated by dendritic $I_{\mathrm{h}}$ in neocortical pyramidal neurons. J Neurophysiol 83:3177-3182.

Wu R-L, Barish ME (1992) Two pharmacologically and kinetically distinct transient potassium currents in cultured embryonic mouse hippocampal neurons. J Neurosci 12:2235-2246.

Wu R-L, Barish ME (1999) Modulation of a slowly inactivating potassium current, $I_{\mathrm{D}}$, by metabotropic glutamate receptor activation in cultured hippocampal pyramidal neurons. J Neurosci 19:6825-6837. 